\title{
Suicide risk, personality disorder and hospital admission after assessment by psychiatric emergency services
}

\author{
Mark Van Veen ${ }^{1,2^{*}}$ (D) André I. Wierdsma ${ }^{3}$, Christine van Boeijen ${ }^{4}$, Jack Dekker ${ }^{5}$, Jeroen Zoeteman ${ }^{5,6}$, \\ Bauke Koekkoek ${ }^{1,7}$ and Cornelis L. Mulder ${ }^{3,8}$
}

\begin{abstract}
Background: The main objectives of the mobile Psychiatric Emergency Services (PES) in the Netherlands are to assess the presence of a mental disorder, to estimate risk to self or others, and to initiate continuity of care, including psychiatric hospital admission. The aim of this study was to assess the associations between the level of suicidality and risk of voluntary or involuntary admission in patients with and without a personality disorder who were presented to mobile PES.

Methods: Observational data were obtained in three areas of the Netherlands from 2007 to 2016. In total, we included 71,707 contacts of patients aged 18 to 65 years. The outcome variable was voluntary or involuntary psychiatric admission. Suicide risk and personality disorder were assessed by PES-clinicians. Multivariable regression analysis was used to explore associations between suicide risk, personality disorder, and voluntary or involuntary admission.

Results: Independently of the level of suicide risk, suicidal patients diagnosed with personality disorder were less likely to be admitted voluntarily than those without such a diagnosis (admission rate .37 versus 46 respectively). However, when the level of suicide risk was moderate or high, those with a personality disorder who were admitted involuntarily had the same probability of involuntary admission as those without such a disorder.

Conclusions: While the probability of voluntary admission was lower in those diagnosed with a personality disorder, independent of the level of suicidality, the probability of involuntary admission was only lower in those whose risk of suicide was low. Future longitudinal studies should investigate the associations between (involuntary) admission and course of suicidality in personality disorder.
\end{abstract}

Keywords: Suicide risk, Personality disorder, Voluntary psychiatric admission, Involuntary admission psychiatric emergency service

\section{Background}

While suicide rates vary considerably between nations and over time, ranging from 3.9 suicides per 100,0000 people in the Eastern Mediterranean to 13.2 in South East Asia, rates of attempted suicide are relatively similar over a wide area [1]. In the Netherlands, injuries caused by suicide attempts led to 93.8 treatments at emergency

\footnotetext{
* Correspondence: vanveenmark@telfort.nl

${ }^{1}$ Research Group for Social Psychiatry and Mental Health Nursing, University of Applied Science, Nijmegen, The Netherlands

${ }^{2}$ Altrecht Mental Health Services, Utrecht, The Netherlands

Full list of author information is available at the end of the article
}

departments and 56.3 general hospital admissions per 100,000 inhabitants in 2015 [2]. Many people who report suicidal thoughts or attempt suicide are seen by Psychiatric Emergency Services (PES), whose main objectives are to assess the presence of a mental disorder, to estimate risk to self or others, and to initiate an intervention (including psychiatric hospital admission). Following attempted suicide, PES often are called upon by general hospital emergency services. In the Netherlands, more often General Practitioners (GP's), ambulance services and the police ask PES for an assessment. Assessing suicide risk is therefore a core task of PES: in the

(c) The Author(s). 2019 Open Access This article is distributed under the terms of the Creative Commons Attribution 4.0 International License (http://creativecommons.org/licenses/by/4.0/), which permits unrestricted use, distribution, and reproduction in any medium, provided you give appropriate credit to the original author(s) and the source, provide a link to the Creative Commons license, and indicate if changes were made. The Creative Commons Public Domain Dedication waiver (http://creativecommons.org/publicdomain/zero/1.0/) applies to the data made available in this article, unless otherwise stated. 
Netherlands, mostly done by a community psychiatric nurse and a psychiatrist. $30 \%$ of a total $150,000-175,000$ assessments each year, are related to suicidal behaviour [3]. Some $16 \%$ of all patients assessed within office hours are admitted to a psychiatric hospital, and some $28 \%$ of those assessed outside office hours. However, regional differences apply (range 5-35\%) $[4,5]$.

\section{Suicide risk, personality disorders and admission}

When the perceived risk of suicide is high, PES may initiate psychiatric hospital admission, either with or without the patient's consent. It is a matter of professional debate whether or not suicidal patients should be admitted: some argue that protection should have the greatest priority [6], while others contend that restricting a patient's autonomy may increase the risk of suicide during and after admission [7, 8]. Importantly, admission cannot prevent suicide [9]. Interestingly, two studies found no association between suicide risk and hospital admission in the Netherlands [10, 11], others found that the probability of involuntary admission was increased by suicide risk in Israel [12], the USA $[13,14]$ and Germany [15].

To date, however, we have found no studies that investigated the interactions between suicidality, admission, and the type of mental disorder. In the absence of empirical evidence, clinical experience suggests that the rate of admission is higher in patients in whom acute suicidality is related to factors such as depression or psychosis than it is in those in whom it is related to having a personality disorder.

While clinicians vary substantially in the ways they perceive suicide risk in patients with a personality disorder (most often a borderline personality disorder), it is unknown whether voluntary or involuntary admission is effective in reducing the level of suicidality. In some cases the level of suicidality may even increase, especially in patients with regressive behaviours, e.g. resulting in physical aggression towards self and others [16-19]. As three qualitative studies have shown, the hospitalisation of chronically suicidal patients may become repetitive, and may intensify suicidal behaviour $[17,20,21]$. Since there are no prospective studies, it is difficult to judge when it is justified to admit a suicidal patient with a personality disorder. Some patients with a personality disorder may get into conflict with staff and other patients during admission, particularly in the case of involuntary admission, resulting in a negative chain of events in which suicidal behaviour, aggression and self-harm increase [20-23].

\section{Aims of the study}

The aim of this study is to assess the association between level of suicide risk, a diagnosis of personality disorder, and risk of voluntary or involuntary admission by the PES. We hypothesized that suicidal patients with a personality disorder have a lower probability of admission.

\section{Methods \\ Study design}

In this observational study we used data from an electronic patient file designed specifically for use in PES, i.e. a web-based clinical support system comprising information on sociodemographic variables, psychiatric symptoms, psychiatric diagnoses and environmental data. We selected data over a ten-year period (20072016) of all patients aged between 18 and 65 seen by mental-health services in the two largest cities in the Netherlands (Amsterdam and Rotterdam) and in one midsize city (Apeldoorn) in a more rural area.

Patients were seen by the PES (a psychiatrist together with a nurse, or a medical doctor or resident in psychiatry, supervised by a psychiatrist) on request of others: usually the general practitioner, but sometimes also on request of the police or an emergency department of a general hospital.

\section{Data collection \\ Sociodemographic variables}

We collected data regarding gender, ethnicity (born in the Netherlands vs. born in another country), ethnicity and age.

\section{Clinical factors}

Clinical factors, including level of suicide risk, were assessed using the Severity of Psychiatric Illness scale (SPI). The SPI was originally developed as a patient-level decision support tool to assess the need for services [24]. It contains 14 items, including level of suicide risk, substance abuse, and danger to others. While two studies $[24,25]$ have used the SPI on an item level rather than a total-score level, we focused on four items that were previously found to be associated with risk of admission [25]: level of suicide risk, level of substance abuse, danger to others, and motivation for treatment. Each item was rated on a 4-point scale from 0 to 3, with 0 indicating no risk and 3 indicating a high risk. The SPI is considered reliable(24)The Dutch version of the SPI had an overall inter-rater reliability of kappa 0.76 [25].

\section{Psychiatric diagnoses}

Clinicians either based their DSM-IV diagnoses on a clinical interview, or adopted the diagnoses from the psychiatric files. These diagnoses were registered in broad categories such as 'psychotic disorder,' 'depressive disorder' or 'personality disorder'. The category 'other' contained diagnoses such as anxiety disorder or PTSD. 
Clinicians also registered different subtypes of personality disorder. For the analyses, we grouped the subtypes of personality disorders together, as no structured interview for assessment of a personality disorder was performed, and therefore the reliability of assessing subtypes of personality disorders in the context of the PES can be questioned. Clinicians could register more than one diagnosis. When personality disorder was registered as one of the diagnoses, this patient was coded as having a personality disorder, beside possible other (axis I or axis II) diagnoses.

\section{Environmental factors}

Family requests for admission were assessed separately on the basis of a dichotomous item asking whether or not the family had requested admission. The level of family involvement was assessed on the basis of one item of the SPI, which was also rated on a 4-point scale from 0 to 3, with 0 indicating significant family involvement and 3 indicating absence of family involvement.

\section{Outcome measure}

Our outcome measure was admission to a psychiatric hospital through the PES, either voluntarily or involuntarily. The four criteria for emergency involuntary admission in the Netherlands are [1] the presence of a mental disorder (this is not specified in Dutch Mental health law, but in practice it is mainly a psychotic, bipolar I, or severe depressive disorder), [2] causing danger to self or others, [3] the lack of an alternative way of averting the danger and [4] unwillingness to be hospitalised.

\section{Statistical analysis}

Descriptive statistics were used to summarize the data on socio-demographic characteristics, clinical factors, diagnoses, and admission (Table 1). Logistic regression analysis was performed to assess the impact of personality disorder,on the association between the level of suicidality and the likelihood of admission, while controlling for gender, age, and danger to others (Table 2). Model comparison was based on the Akaike Information Criterion (AIC). To assess the fit of the final models, we calculated the Hosmer-Lemeshow goodness-of-fit statistic and the area under the receiver operating characteristic (ROC) curve [26].

To explore differences in outcomes when alternative strategies were used, we performed sensitivity analyses. Since risk assessments were grouped within clinicians and service organizations, generalized mixed models were fitted to determine the impact of the hierarchical structure of the data. Next, to control for the fact that the absence of suicidality does not automatically mean that the patient will not be admitted, we explored three approaches other than controlling for danger to others. First, we defined alternative suicide-risk categories; secondly, we split the file into 'no danger to others' and 'low to high danger to others'; and thirdly we restricted suicide risk by excluding patients with no suicide risk and patients with a moderate suicide-risk but a high risk of danger to others. As these approaches produced no relevant differences, we only report models controlling for danger to others. A full account of the sensitivity analyses is available on request from the second author. All statistical analyses were performed using SPSS version 24.0 (SPSS Inc., Chicago, IL).

\section{Results}

A grand total of 71,707 patients were assessed between 2007 and 2016, of which nearly 70\% had been born in the Netherlands. Nearly $30 \%$ of the referrals had been made by GPs; in almost $40 \%$ of these cases, suicidality had been the reason for referral. Over half of the assessed patients $(54.6 \%)$ were suicidal at the time of referral, with at least a moderate or high score on the SPI item. In terms of their diagnoses, over 30\% had a psychotic disorder and over $16.2 \%$ had a personality disorder, mostly a borderline personality disorder (7.2\%), followed by an otherwise unspecified personality disorder (6.4\%), and an anti-social personality disorder (1.4\%). For all characteristics, see Table 1.

The voluntary admission rate was $17.7 \%$ for patients with a low suicide risk, $28.4 \%$ for patients with a moderate risk, and $32.9 \%$ for patients with a high risk. The involuntary admission rate was $18.8 \%$ for patients with a low suicide risk, $16.3 \%$ for patients with a moderate risk and $31.9 \%$ for patients with a high risk.

Table 2 shows that the probability of voluntary admission to a psychiatric hospital for patients with a specific level of suicide risk was affected by the presence of personality disorder. Overall, patients diagnosed with personality disorder were less likely to be admitted than other patients. For patients in the high-suicide risk group the difference in voluntary admission rate between people diagnosed with personality disorder and other diagnosis is estimated at 0.37 versus 0.46 respectively (see Fig. 1a). The interaction effect suggests that when suicide risk increases, the probability of admission for patients with personality disorder increases more rapidly than for patients with no diagnosis of personality disorder. The interaction effect was more distinct in people who had been admitted involuntarily (for involuntary admissions model fit indices are higher). As we controlled for the risk of danger to others - which is strongly associated with involuntary admission - the coefficient for suicide risk is negligible in the model. When the level of suicide risk is moderate or high, the probability of involuntary admission for patients with a 
Table 1 Admission patterns and characteristics in patients assessed by the Psychiatric Emergency Services

\begin{tabular}{|c|c|c|c|c|c|}
\hline & & $\begin{array}{l}\text { Total no. of patients assessed } \\
N=71,707(100 \%)\end{array}$ & $\begin{array}{l}\text { No admission } \\
N=42,572(59 \%)\end{array}$ & $\begin{array}{l}\text { Voluntary admission } \\
N=14,346(20 \%)\end{array}$ & $\begin{array}{l}\text { Involuntary admission } \\
N=14,789(21 \%)\end{array}$ \\
\hline \multicolumn{6}{|l|}{ Sociodemographic variables } \\
\hline \multirow[t]{2}{*}{ Gender } & Male & 55.1 & 57.4 & 19.6 & 23.0 \\
\hline & Female & 44.9 & 61.7 & 20.6 & 17.7 \\
\hline \multirow[t]{3}{*}{ Ethnicity } & Dutch & 67.3 & 59.1 & 21.1 & 19.8 \\
\hline & Other & 8.2 & 54.9 & 17.9 & 27.2 \\
\hline & Unknown & 24.5 & 61.6 & 17.6 & 20.8 \\
\hline \multirow[t]{3}{*}{ Age } & $18-38$ & 49.5 & 59.9 & 18.2 & 21.9 \\
\hline & $39-59$ & 44.4 & 58.8 & 21.7 & 19.5 \\
\hline & $60-65$ & 6.1 & 59.5 & 22.6 & 17.9 \\
\hline \multicolumn{6}{|l|}{ Clinical factors } \\
\hline \multirow[t]{4}{*}{ Suicide risk } & None (0) & 35.4 & 62.0 & 15.9 & 22.1 \\
\hline & Low (1) & 40.3 & 63.5 & 17.7 & 18.8 \\
\hline & Moderate (2) & 16.3 & 55.3 & 28.4 & 16.3 \\
\hline & High (3) & 8.0 & 35.2 & 32.9 & 31.9 \\
\hline \multirow[t]{4}{*}{ Substance abuse } & None (0) & 54.0 & 62.5 & 20.1 & 17.4 \\
\hline & Low (1) & 13.2 & 61.8 & 18.7 & 19.5 \\
\hline & Moderate (2) & 16.1 & 56.7 & 17.9 & 25.4 \\
\hline & High (3) & 16.7 & 50.1 & 22.7 & 27.2 \\
\hline \multirow[t]{4}{*}{ Danger to others } & None (0) & 54.3 & 72.1 & 21.9 & 5.9 \\
\hline & Low (1) & 30.3 & 56.5 & 20.7 & 22.8 \\
\hline & Moderate (2) & 8.5 & 25.9 & 15.4 & 58.7 \\
\hline & High (3) & 7.0 & 13.1 & 7.4 & 79.4 \\
\hline \multirow[t]{4}{*}{ Motivation for treatment } & None (0) & 25.4 & 75.7 & 22.9 & 1.3 \\
\hline & Low (1) & 31.2 & 64.4 & 30.8 & 4.8 \\
\hline & Moderate (2) & 22.2 & 54.8 & 17.4 & 27.8 \\
\hline & High (3) & 21.2 & 37.1 & 3.5 & 59.4 \\
\hline \multicolumn{6}{|l|}{ Psychiatric diagnoses } \\
\hline \multirow[t]{3}{*}{ Diagnosis axis I DSM-IV } & Depressive disorder & 12.6 & 63.6 & 28.7 & 7.7 \\
\hline & Psychotic disorder & 32.1 & 38.8 & 20.3 & 40.9 \\
\hline & Other & 55.3 & 68.9 & 20.0 & 11.1 \\
\hline Diagnosis axis II DSM IV & Personality disorder ${ }^{a}$ & 16.2 & 62.8 & 23.0 & 14.2 \\
\hline \multicolumn{6}{|l|}{ Environmental factors } \\
\hline \multirow{3}{*}{$\begin{array}{l}\text { Admission requested } \\
\text { by family }\end{array}$} & Not applicable & 58.3 & 66.3 & 15.9 & 17.8 \\
\hline & Yes & 28.0 & 28.3 & 36.6 & 35.1 \\
\hline & No & 13.7 & 93.3 & 3.7 & 3.1 \\
\hline \multirow[t]{4}{*}{ Family involvement } & None (0) & 44.1 & 61.4 & 21.0 & 17.6 \\
\hline & Low (1) & 21.4 & 60.2 & 19.9 & 19.9 \\
\hline & Moderate (2) & 15.7 & 58.5 & 20.0 & 21.6 \\
\hline & High (3) & 18.8 & 54.4 & 17.8 & 27.9 \\
\hline
\end{tabular}

a11 subtypes of personality disorder (according to DSM-IV) grouped together

personality disorder is the same as that for patients with other disorders (see Fig. 1b).

The probability of (in)voluntary admission was also affected by other variables. An effect of motivation for treatment (main effect $-2.80, \mathrm{SE}=.061$; interaction effect $-0.257, \mathrm{SE}=.042$ ) indicated that involuntary admission was higher in patients with less motivation for treatment. Substance abuse did not change the effect 
Table 2 Probability of voluntary or involuntary admission in patients with suicide risk and personality disorder

\begin{tabular}{lllll}
\hline & Voluntary admission B (SE) & Exp (B) & Involuntary admission B (SE) & Exp (B) \\
\hline Intercept $^{\text {a }}$ & $-1.395(.020)$ & & $-1.158(.033)$ & $-0.037(.018)$ \\
Suicide risk & $0.398(.013)$ & 1.49 & $-0.929(.080)$ & 0.96 \\
Personality disorder & $-0.508(.049)$ & 0.60 & $0.307(.045)$ \\
Interaction effect & $0.142(.031)$ & 1.15 & -63.3 \\
AIC ${ }^{b}$ & -32.3 & & 0.80 \\
AUC & .72 & & 1.36 \\
\hline
\end{tabular}

${ }^{a}$ Controlling for age (grand-mean centered), gender (effect-coded), and danger to others

${ }^{\mathrm{b}} \mathrm{AIC}$ in smaller-is-better-form, comparing models with and without interaction effect

of personality disorder on the association between suicide risk and the probability of admission. Family requests for admission increased the probability of voluntary admission, which rose in line with the level of suicide risk (main effect $1.59, \mathrm{SE}=.036$; interaction effect $0.105, \mathrm{SE}=.026)$. Family support was also apparent in the assessment for involuntary admission but not in combination with suicide risk. Patients who had strong family involvement were less likely to be admitted to hospital, and were even less likely to be admitted when their suicide risk was higher (main effect -0.114 , SE $=.032$; interaction effect $-0.057, \mathrm{SE}=.024$ ). While these

\section{a}
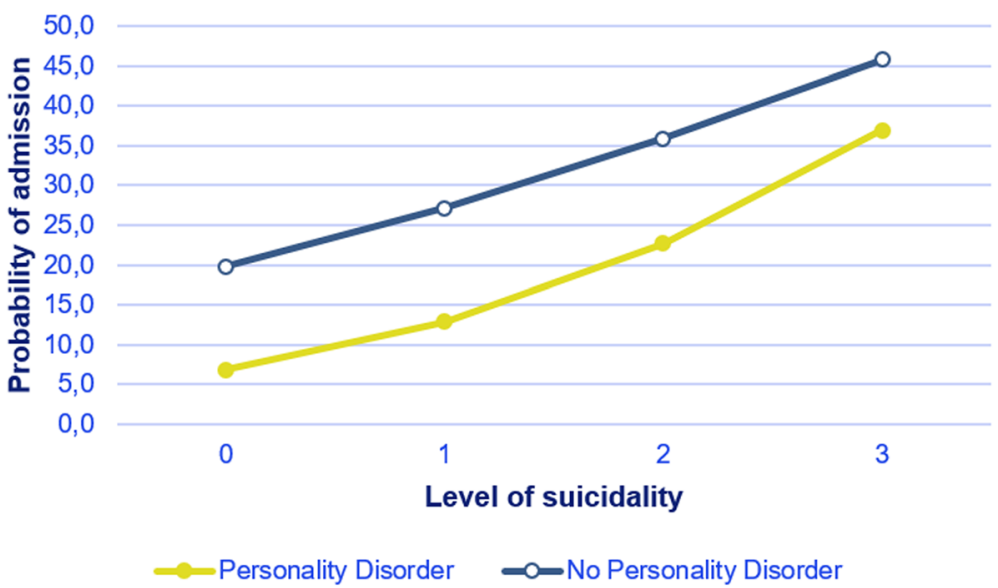

b

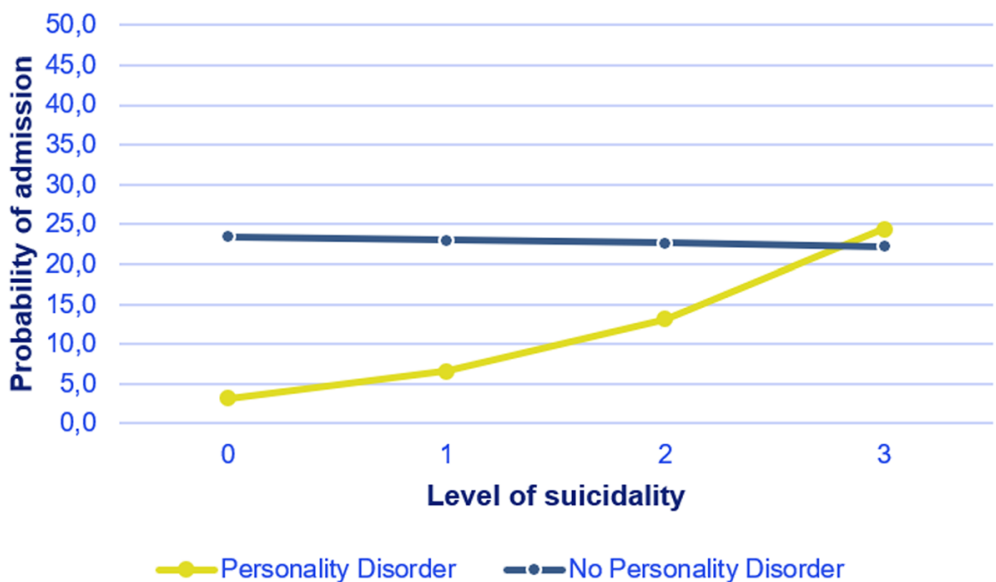

Fig. 1 a Voluntary admission by suicide risk and personality disorder (or no personality disorder) at fixed values for age gender and danger to others. $\mathbf{b}$ Involuntary admission by suicide risk and personality disorder (or no personality disorder) at fixed values for age, gender, and danger to others 
factors are important, they did not change the associations between level of suicide risk, personality disorder and (in)voluntary admission.

\section{Discussion}

This study shows that suicidal patients diagnosed with a personality disorder are less likely to be voluntarily admitted to a psychiatric hospital by PES, as compared to patients not diagnosed with a personality disorder However, when suicide risk is higher, the personality disorder diagnosis becomes irrelevant in the case of an involuntary admission.

These findings partly confirm the speculation amongst clinicians that admission may be less effective and possibly harmful to people with a personality disorder. Apparently, clinicians working in the PES think that unless suicide risk is very high, suicidal patients with a personality disorder should not be admitted. We speculate that this might be due to fear for a deterioration of the clinical state of patients who have been admitted with a personality disorder.

Strong family support was also associated with a lower chance of both voluntary and involuntary admission, while family pressure on admission was associated with increased chances of (in)voluntary admission. A previous study showed similar results: when significant others requested admission, the probability of admission increased [27]. Family and friends also gave practical support and motivated patients to get better and adhere to their treatment, which decreased the probability of admission. The same study also showed that admission as the last available option is more likely to be unavoidable when family or other close relatives indicate that they can no longer provide help.

\section{Clinical significance and implications}

When deciding on admission of a suicidal patient, PES professionals find themselves facing a recurrent dilemma: that admission might be harmful and increase suicidal behaviour - particularly in patients with a personality disorder - but that outpatient follow-up might not be safe enough. Data are lacking about both the effects on suicide risk of inpatient interventions [28]), as well as outpatient interventions such as Intensive Home Treatment (IHT). IHT can be seen as an alternative to admission, offers a multi-disciplinary approach and provides intensive community-based support and appropriate therapeutic interventions to patients and their families [29]. However, little is known about its effectiveness in prevention of suicide and a recent study suggests high suicide rates in IHT-patients [30], although causality remains unknown.

Another alternative to a voluntary admission to a psychiatric hospital may lie in respite houses that focus on a patient's autonomy, empowerment and responsibility
[31]. Patients can stay in such houses for a short while, accompanied by volunteers [31]. While this is promising, and may not lead to increased suicidal behaviour in patients with a personality disorder, there is as yet limited evidence of their effectiveness [32].

\section{Strengths and limitations}

To our knowledge, this is the first study to describe the relationship between the level of suicide risk, personality disorder and psychiatric hospital admission. It nonetheless has some limitations. First, as personality disorders were diagnosed on the basis not of structured interviews, but on information gathered during the assessment by PES, some diagnoses may have been missing or incorrect. Therefore we grouped the various types of personality disorder together. Second, the assessment of suicide risk was based on one item of the SPI, and also not on a structured interview. Given the nature and pressure of working in the PES, however, using structured interviews is difficult. Third, as all data were collected in clinical practice, they were vulnerable to errors or missing data in some variables (ethnicity, age).

\section{Conclusions}

After controlling for sociodemographic, clinical factors, psychiatric diagnoses and environmental factors, we intended this study to assess the association between level of suicidality and risk of voluntary or involuntary admission in patients presenting at the mobile PES with or without a personality disorder. We found that, independently of the level of suicide risk, suicidal patients diagnosed with a personality disorder were less likely to be admitted voluntarily than those without such a diagnosis. In involuntary admitted patients, however, personality disorder affected the probability of admission only in those whose risk of suicide was low Longitudinal studies are needed to better understand the associations between (in)voluntary admission and the course of suicidality in personality disorder patients.

\section{Abbreviations \\ PES: Psychiatric Emergency Service; SPI: Severity of Psychiatric Illness rating scale}

\section{Acknowledgements}

Not applicable.

Funding

Not applicable.

Availability of data and materials

Upon reasonable request, the data are available from the corresponding author

Author's contributions

Study conceptualization and data collection: AW, CvB, JD, JZ, NM. Analysis and interpretation of data: MVV, AW, BK, NM. Drafting the article or revising it critically for important intellectual content: MvV, AW, CVB, JD, JZ, BK, NM. Final approval of the version to be published: MvV, AW, CVB, JD, JZ, BK, NM. 


\section{Ethics approval and consent to participate}

Data from the electronic patient files were used strictly anonymously, and patients were not submitted to any specific action related to the study, and therefore according to Dutch Law on Medical Ethics [33], no specific informed consent or a review of a Medical Ethics Committee was required.

\section{Consent for publication}

Not applicable.

\section{Competing interests}

The authors declare that they have no competing interests.

\section{Publisher's Note}

Springer Nature remains neutral with regard to jurisdictional claims in published maps and institutional affiliations.

\section{Author details \\ ${ }^{1}$ Research Group for Social Psychiatry and Mental Health Nursing, University of Applied Science, Nijmegen, The Netherlands. ${ }^{2}$ Altrecht Mental Health Services, Utrecht, The Netherlands. ${ }^{3}$ Epidemiological and Social Psychiatric Research Institute, Department of Psychiatry, Erasmus MC, Rotterdam, The Netherlands. ${ }^{4} \mathrm{GGNet}$ Mental Health Services, Apeldoorn, The Netherlands. ${ }^{5}$ Faculty of Behavioural and Movement Sciences, VU Faculties, Amsterdam, The Netherlands. ${ }^{6}$ Arkin Mental Health Care, Department of Emergency Psychiatry, Amsterdam, The Netherlands. ${ }^{7}$ Pro Persona Mental Health Services, Wolfheze, The Netherlands. ${ }^{8}$ Parnassia Psychiatric Institute, Rotterdam, The Netherlands.}

Received: 3 February 2019 Accepted: 6 May 2019

Published online: 23 May 2019

\section{References}

1. WHO. GHO | By category / Life expectancy - Data by WHO region [Internet]. WHO. World Health Organization; 2016 [cited 2018 Jun 18]. Available from: http://apps.who.int/gho/data/view.main.MHSUICIDEASDRREGv?lang=en

2. Gommer AM GR. Onderzoek naar schatting van landelijk aantal SEHbezoeken op basis van Letsel Informatie Systeem (LIS) : the validity of the estimates of the national number of visits to emergency departments on the basis of data from the injury surveillance system LIS. RIVM Rapp [Internet]. 2016 Jun 16 [cited 2018 Sep 6];2015-0217. Available from: http:// rivm.openrepository.com/rivm/handle/10029/613654.

3. De Winter R, De Croot M, Van Dassen M, Deen M, De Beurs D. Het vóórkomen van suicidaal gedrag en suicidepogingen bij de psychiatrische crisisdienst (preventing suicidal behaviour and suicide attemps by PES). Tijdschr Psychiatr [Internet]. 2017 [cited 2018 Oct 26]; 59(3):140-149. Available from: http://www.tijdschriftvoorpsychiatrie.nl/ issues/511/articles/11262.

4. de Leeuw R, Peters A, van Hemert B, van Houdt C, Schrijvers G. GGZ crisisdiensten: grote verschillen in organisatie en wijze van functioneren (PES: large differences in organisation and way of functioning). Julius centrum UMC Utrecht [internet]. 2009 [cited 2018 Jun 11]; Available from: https://www.medicalfacts.nl/2009/11/23/grote-verschillen-tussen-ggzcrisisdiensten/.

5. Stobbe J, de Leeuw JRJ, Mulder CL. Werkwijze van ambulante psychiatrische crisisdiensten in Nederland (Methods in psychiatric emergency services in the Netherlands). Tijdschr Psychiatr [Internet]. 2016 [cited 2018 Sep 6];58(9): 624-631. Available from: http://www.tijdschriftvoorpsychiatrie.nl/assets/ articles/58-2016-9-artikel-stobbe.pdf.

6. Jacobs DG, Ross Baldessarini CJ, Conwell Y, Fawcett JA, Horton L, Meltzer H, et al. Practice guideline for the assessment and treatment of patients with suicidal behaviors [internet]. 2010 [cited 2018 Nov 21]. Available from: https:/psychiatryonline.org/pb/assets/raw/sitewide/practice_guidelines/ guidelines/suicide.pdf

7. Hunt IM, Kapur N, Webb R, Robinson J, Burns J, Turbull P, et al. Suicide in current psychiatric in-patients: a case-control study: the National Confidential Inquiry into suicide and homicide. Psychol Med [Internet]. 2007 Jun 19 [cited 2018 Jul 5];37(6):831-837. Available from: http://www.journals. cambridge.org/abstract_S0033291707000104

8. Sinclair JMA, Hawton K, Gray A. Six year follow-up of a clinical sample of self-harm patients. J Affect Disord [Internet]. 2010 Mar 1 [cited 2018 Jul 5];
121(3):247-252. Available from: https:/www.sciencedirect.com/science/ article/pii/S0165032709002353

9. Van Hemert AM, Kerkhof AJFM, De Keijser J, Verwey B, Van Boven C, Hummelen JW, et al. Samenvatting MDR diagnostiek en behandeling van suicidaal gedrag [Summary MDG diagnostic and treatment of suicidal behaviour]. [Internet]. 2012 [cited 2018 Jun 11]. 1-454 p. Available from: https://assets-sites.trimbos.nl/docs/763ed30c-00e4-45d4-9e6bbdc925c01921.pdf.

10. Mulder CL, Koopmans GT, Lyons JS. Determinants of indicated versus actual level of care in psychiatric emergency services. Psychiatr Serv [Internet]. 2005 Apr [cited 2018 Feb 5];56(4):452-457. Available from: http:// psychiatryonline.org/doi/abs/10.1176/appi.ps.56.4.452

11. Unick GJ, Kessell E, Woodard EK, Leary M, Dilley JW, Shumway M. Factors affecting psychiatric inpatient hospitalization from a psychiatric emergency service. Gen Hosp Psychiatry [Internet]. 2011 Nov [cited 2018 Jun 19];33(6): 618-625. Available from: http://www.ncbinlm.nih.gov/pubmed/21816482

12. Rabinowitz J, Massad A, Fennig S. Factors influencing disposition decisions for patients seen in a psychiatric emergency service. Psychiatr Serv [Internet]. 1995 [cited 2018 Feb 12];46(7):712-718. Available from: http:// europepmc.org/abstract/med/7552564

13. Lyons JS, Stutesman J, Neme J, Vessey JT, O'Mahoney MT, Camper HJ. Predicting psychiatric emergency admissions and hospital outcome. Med Care [Internet]. 1997 Aug [cited 2018 Feb 5];35(8):792-800. Available from: http://www.ncbi.nlm.nih.gov/pubmed/9268252

14. Engleman NB, Jobes DA, Berman AL, Langbein LI. Clinicians' decision making about involuntary commitment. Psychiatr Serv [Internet]. $1998 \mathrm{Jul}$ [cited 2018 Feb 5];49(7):941-945. Available from: http://www.ncbi.nlm.nih. gov/pubmed/9661230

15. Way BB, Banks S. Clinical factors related to admission and release decisions in psychiatric emergency services. Psychiatr Serv [Internet]. 2001 Feb [cited 2018 Feb 5];52(2):214-218. Available from: http://psychiatryonline.org/doi/ abs/10.1176/appi.ps.52.2.214

16. Paris J. Chronic suicidality among patients with borderline personality disorder. Psychiatr Serv [Internet]. 2002 Jun 1 [cited 2018 Apr 24];53(6):738-742. Available from: http://psychiatryonline.org/doi/abs/10.1176/appi.ps.53.6.738

17. Paris J. Is Hospitalization Useful for Suicidal Patients with Borderline Personality Disorder? J Pers Disord [Internet]. 2004 Jun 1 [cited 2018 May 17];18(3):240-247. Available from: http://guilfordjournals.com/doi/10.1521/ pedi.18.3.240.35443

18. Oldham JM. Borderline personality disorder and suicidality [Internet]. Vol. 163, American Journal of Psychiatry. American Psychiatric Publishing; 2006 [cited 2018 May 24]. p. 20-6. Available from: http://psychiatryonline.org/doi/ abs/10.1176/appi.ajp.163.1.20

19. Goodman M, Roiff T, Oakes AH, Paris J. Suicidal risk and management in borderline personality disorder [Internet]. Vol. 14, Current Psychiatry Reports. 2012 [cited 2018 May 24]. p. 79-85. Available from: http://www.ncbi.nlm.nih. gov/pubmed/22113831

20. Látalová K, Praško J. Aggression in borderline personality disorder [internet]. Vol. 81, Psychiatric quarterly. Springer US; 2010 [cited 2018 may 24]. p. 239-251. Available from: http://link.springer.com/10.1007/s11126-010-9133-3

21. Elisei S, Verdolini $\mathrm{N}$, Anastasi S. Suicidal attempts among emergency department patients: one-year of clinical experience. In: Psychiatria Danubina [internet]. 2012 [cited 2018 may 24]. p. 140-2. Available from: http://www.ncbi.nlm.nih.gov/pubmed/22945208.

22. Hayashi N, Igarashi M, Imai A, Osawa Y, Utsumi K, Ishikawa Y, et al. Psychiatric disorders and clinical correlates of suicidal patients admitted to a psychiatric hospital in Tokyo. BMC Psychiatry [Internet]. 2010 Dec 13 [cited 2018 May 24];10(1):109. Available from: http://bmcpsychiatry.biomedcentral. com/articles/10.1186/1471-244X-10-109

23. Comtois KA, Carmel A. Borderline personality disorder and high utilization of inpatient psychiatric hospitalization: concordance between research and clinical diagnosis. J Behav Health Serv Res [Internet]. 2016 Apr 30 [cited 2018 May 24];43(2):272-280. Available from: http://link.springer.com/10. 1007/s11414-014-9416-9

24. Lyons JS, Colletta J, Devens M, Finkel SI. Validity of the severity of psychiatric illness rating scale in a sample of inpatients on a psychogeriatric unit. Int Psychogeriatrics [Internet]. 1995 Sep [cited 2018 Feb 12];7(3):407-416. Available from: http://www.journals.cambridge.org/abstract_S1041610295002158

25. Mulder CL, Broer J, Uitenbroek D, van Marle P, van Hemert AM, Wierdsma Al. [Accelerated increase in the number of involuntary admissions following the implementation of the Dutch Act on Compulsory Admission to 
Psychiatric Hospitals (BOPZ)]. Ned Tijdschr Geneeskd [Internet]. 2006 Feb 11 [cited 2018 Feb 5];150(6):319-322. Available from: http://www.ncbi.nlm.nih. gov/pubmed/16503024

26. Hosmer DW, Lemeshow S. Applied logistic regression, vol. 373: Wiley; 2000. Available from: http://resource.heartonline.cn/20150528/1_3kOQSTg.pdf.

27. van der Post L, Mulder CL, Bernardt CML, Schoevers RA, Beekman ATF, Dekker J. Involuntary admission of emergency psychiatric patients: report from the Amsterdam study of acute psychiatry. Psychiatr Serv [Internet]. 2009 Nov [cited 2018 Feb 5];60(11):1543-1546. Available from: http://www. ncbi.nlm.nih.gov/pubmed/19880477

28. Borschmann R, Moran P. Crisis management in borderline personality disorder. Int J Soc Psychiatry [Internet]. 2011 Jan 29 [cited 2018 Jun 11]; 57(1):18-20. Available from: http://www.ncbi.nlm.nih.gov/pubmed/21252352

29. Jethwa K, Galappathie N, Hewson P. Effects of a crisis resolution and home treatment team on in-patient admissions. Psychiatr Bull [Internet]. 2007 [cited 2018 Jul 5];31(5):170-172. Available from: https://www.i-ht.nl/wpcontent/uploads/2014/03/Effects-of-an-intensive-home-treatment-serviceon-admission-rates-2007-Leeds-UK-kopie.pdf

30. Hunt IM, Appleby L, Kapur N. Suicide under crisis resolution home treatment a key setting for patient safety. BJPsych Bull [Internet]. 2016 Aug 2 [cited 2018 Jul 10];40(04):172-174. Available from: https://www.cambridge.org/core/ product/identifier/S2056469400002035/type/journal_article

31. Huber MA. Nu heb ik de sleutel [Now l've got the key].. [cited 2018 Jun 19]; Available from: https://pure.hva.nl/ws/files/4007935/2017_Huber_M.A. 2017_Nu_heb_ik_de_sleutel._Onderzoek_naar_zelfbeheer_in_Participatie_ Herstel_juni_2017.pdf

32. Clark F, Khattak S, Nahal J. Crisis Resolution and Home Treatment: The Service User and Carer Experience. Heal (San Fr. 2008;(November). Available from: https://www.nao.org.uk/wp-content/uploads/2007/12/crisis_ resolution_home_treatment.pdf.

33. CCMO. Uw onderzoek: WMO-plichtig of niet? [your research: Medical Ethics Committy necessary?] [Internet]. [cited 2019 May 5]. Available from: https:// www.ccmo.nl/onderzoekers/wet-en-regelgeving-voor-medischwetenschappelijk-onderzoek/uw-onderzoek-wmo-plichtig-of-niet

Ready to submit your research? Choose BMC and benefit from:

- fast, convenient online submission

- thorough peer review by experienced researchers in your field

- rapid publication on acceptance

- support for research data, including large and complex data types

- gold Open Access which fosters wider collaboration and increased citations

- maximum visibility for your research: over $100 \mathrm{M}$ website views per year

At $\mathrm{BMC}$, research is always in progress.

Learn more biomedcentral.com/submissions 